DR BONITA MASON is a journalism lecturer in the School of Media, Creative Arts and Social Inquiry at Curtin University, Perth.

\section{Intervention in Aboriginal communities examined}

'And there'll be NO dancing': Perspectives on policies impacting Indigenous Australia since 2007, edited by Elisabeth Baehr and Barbara Schmidt-Haberkamp. Cambridge, UK: Cambridge Scholars Publishing, 2017. 354 pp. ISBN 9781443898638

$T$ HE PAST is now with us; it never went away.'

The 2007 Intervention into the lives of Aboriginal people living in the Northern Territory was a low point in the relationship between the Australian government and Indigenous people.

As one of the Aboriginal authors in No Dancing, Warraimay historian Victoria Grieves puts it, the Northern Territory Emergency Response (NTER), as the Intervention was officially known, 'leaves no doubt about the relationship of Aboriginal people to the settler colonial state' (p. 89).

At the time, the scale of the Intervention seemed a drastic departure from previous government actions. However, this book argues that it was yet another poorly conceived and executed intrusion into Aboriginal lives. Any pretence of

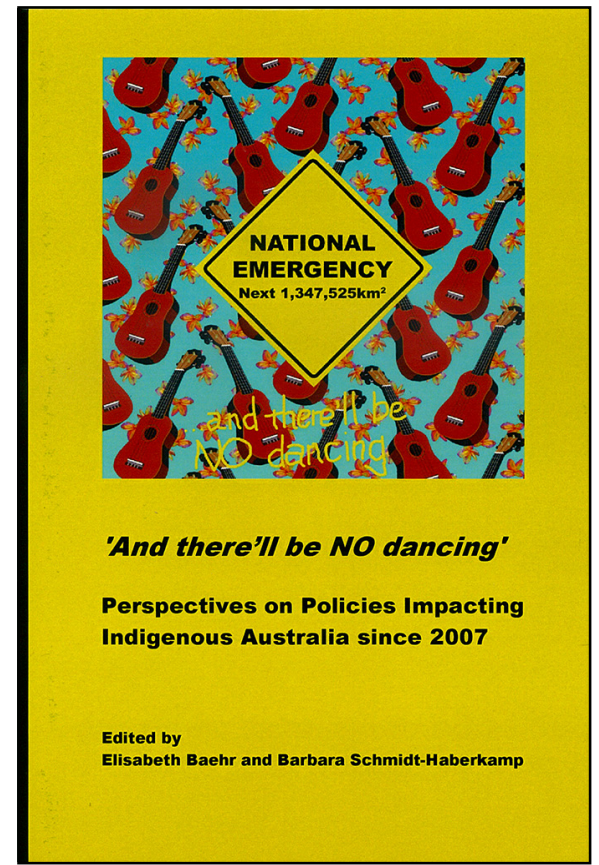

the usual good intentions were gone and something more transparently cynical was happening in the continuing Australian colonial project.

In June 2007, a conservative Australian government used the release of a Northern Territory government report on the protection of Indigenous children from sexual abuse-Ampe Akelyernemane Meke Mekarle/Little Children are Sacred - to construct an Indigenous child abuse emergency. Although the Intervention acted against the report's recommendations for empowering and working with Aboriginal communities to reduce child sexual abuse, the government used the report to justify sending in the military and an army of public servants to take control of prescribed NT Aboriginal communities.

It also enacted controls on income, health, education, local governance, 
land, employment, alcohol, and pornography that required the suspension of the Racial Discrimination Act. Statutory restrictions on land rights further impeded Aboriginal autonomy. These actions breached Australia's international responsibilities to uphold the human rights of its Indigenous citizens.

After five years the Labor government continued many aspects of the Intervention for another decade through its Stronger Futures legislation. McCallum and Waller (2017, p. 6) note that Indigenous Australian people's lives 'have been more tightly governed and policed by federal and state policy ... than any other group of Australians'. They also quote policy specialists Johns and Saunders, who said: 'Dealing with Indigenous people is a litmus test of Australian nationhood by which the larger world will judge us.' (p. 5)

Baehr and Schmidt-Haberkamp's edited collection is an example of judgement from the world. It arose from a German Association for Australian Studies workshop on The Intervention and its Consequences at Bonn University. It places the Intervention in its political and historical context, assesses the extent to which it met and failed to meet its stated objectives and examines discourses and narratives surrounding the Intervention, including those coming out of the news media. The editors seek to promote debate on Indigenous self-determination, human rights and culture.

We expect that the bitter irony of a workshop in Germany analysing racism and discrimination in Australia will raise hackles, but we also hope it will raise the alarm concerning the interventions. (Baehr \& SchmidtHaberkamp, p. 4)

The editors are two of the sixt German authors contributing to the book. Of the remaining eight authors, all of whom are Australian or have Australian connections, two are Aboriginal and one is an Australian journalism academic. The 14 chapters present a well-structured, readable and comprehensive collection of case studies focused on the Intervention or the forces and conditions that helped to create it.

They are written for an international readership, and present a range of disciplines and fields - history, land rights, law, human rights, journalism, literature, film, art, sport, education, post-colonial studies and disability. The book shows how past interventions have consistently failed to meet their objectives and made the circumstances of the Indigenous peoples subjected to them worse.

In its general construction of the circumstances of many Aboriginal lives as the fault of Indigenous individuals and dysfunction associated with Aboriginal cultures, rather than the result of a history of misguided and often damaging government policies and actions, the Australian media effectively legitimised the intervention. Journalists too often failed to scrutinise government claims against readily available evidence that the Intervention worsened many of the social measures it was meant to improve. 
At the heart of the book is the idea that narrative expresses and enacts power relations. Just as the justification for the Intervention bears little relationship to the findings and recommendations of the report that supposedly triggered it, journalism academic Michelle Dunne Breen (p. 170) finds that 'media reporting gave a critically false impression of the LSCAS's [ Little Children are Sacred report] content'. The bulk of the report was devoted to identifying risk factors and ways of reducing them, which the government and media largely ignored.

Her analysis indicates inaccuracies and significant omissions demonstrating 'inter-media agenda-setting and pack reporting' (p. 179). She found 'discursive collusion between the minister [for Indigenous Affairs] and the reporters (in that the reporters aped what the minister said), and the construction, along a discourse train, of false claims as truth' (p. 174).

Another chapter deals with the absence of Indigenous and alternative voices in an official narrative founded on the Intervention's legal documents (Althans). Narratives of Australian citizenship are central to Aboriginal Studies. Professor and Pitjantjatjara descendent Barry Judd calls the Intervention a return to pre-1967 policies when 'Indigenous people were formally denied the rights associated with national citizenship' (p. 110).

Other chapters continue the theme of narrative power and highlight the potential of literature, film and art 'to intervene in dominant discourses about the legitimacy of the Intervention' (Klein, p. 217). Birk (p. 200) argues that fiction, including post-Intervention stories about children such as The Chainsaw File and Fog a Dox by Indigenous author Bruce Pascoe can aid 'trans-cultural understanding' (p. 210) and help imagine a different future.

Baehr and Schmidt-Haberkamp (p. 4) suggest no 'new solutions'. Rather than a concluding chapter pulling the threads together and delivering some final insights, they let the individual chapters speak for themselves, although they do urgently call for 'new visions' (p. 4). However, a final chapter, possibly from NT Aboriginal voices imagining a different path, could have usefully been added to the collection.

Both Aboriginal authors in the book suggest elements of possible solutions: one at the level of the nation state (Grieves); the other through an 'On Country' Aboriginal football league (Judd). After setting out the ways in which Australian Indigenous people are effectively denied full citizenshipand often humanity - Grieves suggests how an inclusive Australia could be founded. Judd uses the development of the Wilurarra Tjutaku Football League in Central Australia as an example of how Indigenous people can strengthen their cultures and identities by becoming increasingly separate, at least in some respects, from settler-Australia.

Indigenous policy-making in Australia is hampered by the lack of a workable framework for the relationship between Indigenous peoples and governments. In 2008, Yawuru leader 
Peter Yu chaired a review into the effectiveness of the Intervention, which found that: 'The most essential element in moving forward is for government to re-engage with the Aboriginal people of the Northern Territory' (p. 11).

In November 2017, The Referendum Council issued an Australiawide Indigenous 'Statement From the Heart'. The statement called for an Indigenous voice in the Australian Constitution, truth-telling about the past and a commission to oversee a process of agreement-making between first and settler Australia:

We seek constitutional reforms to empower our people and take a rightful place in our own country. When we have power over our destiny our children will flourish. They will walk in two worlds and their culture will be a gift to their country. (Referendum Council, 2017)

The Australian government responded with an emphatic 'No'.

\section{References}

McCallum, K. \& Waller, L. (2017). The dynamics of news and indigenous policy in Australia. Bristol, UK/Chicago, USA: Intellect, The University of Chicago Press.

Referendum Council (2017, May). Uluru statement from the heart. Retrieved from: www.referendumcouncil.org. au/event/uluru-statement-from-theheart 0.PDF.

Yu, P., Duncan, M. E., \& Gray, B. (2008). Report of the NTER Review Board. Canberra: Commonwealth of Australia.
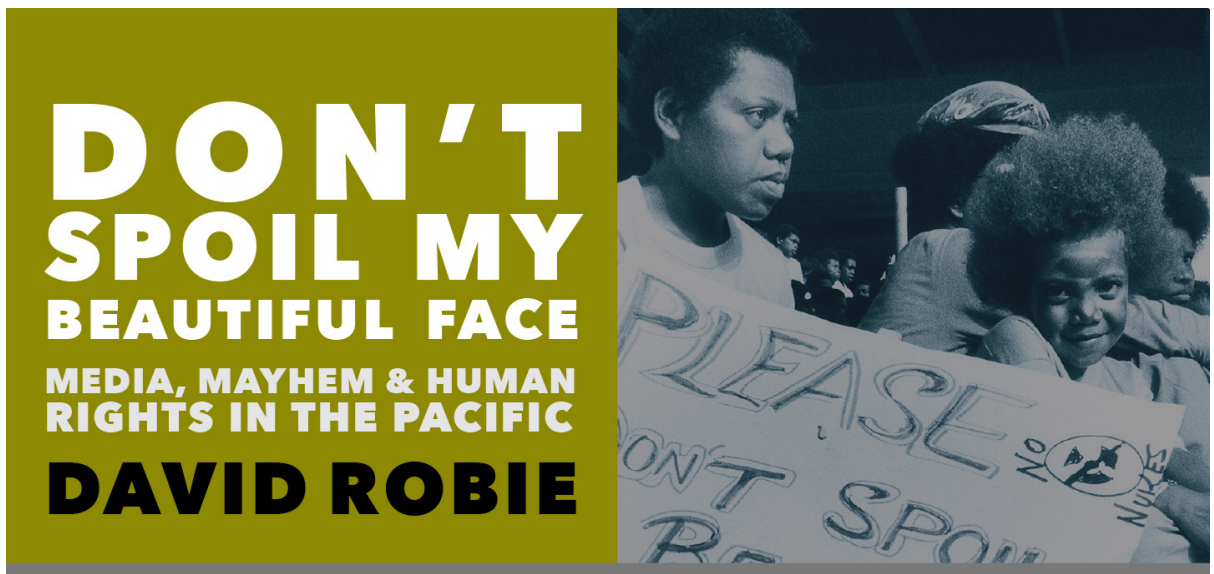

"This is an extraordinary 'secret history' of a vast region of the world of which David Robie has been a rare expert witness. What makes this epic work so timely is that it allows us to understand the Asia-Pacific at a time of renewed cold war ambitions and dangers." - John Pilger

little island press • ISBN 978-1-877484-25-4 • www.littleisland.co.nz 